\title{
EDITORIAL
}

\section{Crise ambiental, direito e desenvolvimento}

A Prim@ Facie, Revista do PPGCJ, da UFPB, em seu número 44, depara-se novamente com a crise ambiental, desta vez acentuada pelas contradições interfinanceiras do capitalismo global. Quais os limites e as repercussões do modelo atual de desenvolvimento na discussão do direito ambiental? Como enfrentar, juridicamente, sem perder a centralidade da questão nacional, a expansão da fronteira agrícola, o desemprego, a concentração fundiária, a precarização do ambiente nas cidades e a espoliação de bens, terras e direitos diante da crise ambiental? Esses são alguns dos questionamentos que perpassam este número.

A resposta das multinacionais privadas, associadas aos seus Estados Nacionais, à crise ambiental é, para seguirmos a terminologia de David Harvey ${ }^{1}$, a pressão por uma nova configuração econômica que exproprie os bens comuns, tais como o ar, a água, a terra, as florestas, transformando em mercadorias os bens ambientais, a cultura e a produção do conhecimento, privatizando os bens públicos

${ }^{1}$ HARVEY, David. O novo imperialismo. São Paulo: Edições Loyola, 2003, p. 121, 133. 
e reduzindo os direitos de propriedade em geral a direitos exclusivos de propriedade privada. Harvey chama isto de acumulação por espoliação, desapossamento ou despossessão² ${ }^{2}$

Neste exato momento, a nova administração dos EUA tenta buscar um consenso com o centro do capitalismo (Europa, Japão e Austrália). Querem unificar o mundo ocidental das finanças para, tomando medidas aparentemente multilaterais, fortalecer um mundo unipolar a partir dos seus interesses. Um dos movimentos de Joe Biden é a retomada do Acordo de Paris, mas na tentativa de resolver o problema das mudanças climáticas pelo apoderamento dos recursos naturais renováveis e pela imposição de um controle sobre os bens comuns, a exemplo da água, da luz solar e das massas de ar, de alto potencial energético, dos países do terceiro mundo.

É o lado controverso que não é mostrado explicitamente nas propostas dos EUA e dos seus aliados do G7 para a celebração dos acordos ambientais, nem mesmo nos mais diversos Congressos e Fóruns de Direito Ambiental no Brasil. As alternativas que o Norte oferece para a crise ambiental passam pelo aumento da taxa de exploração da força de trabalho e do desapossamento sobre o campesinato, as massas operárias, os povos originários, as comunidades tradicionais e as parcelas menos abastadas das camadas médias urbanas.

No Brasil, vastas áreas de terra estão sendo apropriadas pelas empresas estrangeiras de energia eólica e solar, com o "objetivo" de assegurar esta estratégia, mascarada por argumentos de forte carga tópica, como o desenvolvimento sustentável, uma espécie de agenda verde dos países ricos, vinda desde a Conferência de Estocolmo de 1972, que não toca nas desigualdades sociais e na divisão injusta do trabalho e da produção no planeta, e que inaugura uma série de documentos ambientais internacionais no mesmo sentido. A "agenda

${ }^{2}$ Idem, ibidem, p. 121-126. 
verde" tem uma continuação com o documento "O nosso futuro comum” (fruto da Conferência da Eco-92, no Rio de Janeiro) e um prosseguimento com o documento "O futuro que queremos" (Conferência das Nações Unidas sobre o Desenvolvimento Sustentável, a Rio+20), é "recauchutada” pelo Acordo de Paris e esconde a pressão para a remoção das populações do campo, a restrição do uso da terra, a privatização dos bens comuns e a disputa por fontes potenciais de energia, a exemplo do sol e dos ventos. Mariana Traldi 3 chama este processo de apropriação de terras pela indústria de green grabbing, versão "verde" de desapossamento, que tem sua face mais recente na transição energética imposta pelo capital no Brasil, com o estímulo à desindustrialização do país, o lançamento de vastas áreas de terras no mercado e o aprofundamento da insegurança alimentar de comunidades e territórios inteiros 4 . Nesse sentido, a causa da crise ambiental, ao contrário do que sustenta Enrique Leff5, não está em qualquer crise do sujeito ou do conhecimento, mas no processo de produção e de circulação do capital.

Não bastasse isso, os erros da política ambiental no Brasil começam a dar margem à queixa das grandes potências capitalistas sobre a nossa Amazônia. Trata-se de uma campanha orquestrada pelos EUA e o seu quintal europeu (muito mal intencionada) para alimentar seus próprios interesses contra a América Latina, que nada têm de ambientais. Os norte-americanos e os europeus têm objetivos bem determinados, não se importam conosco e estão sempre se aproveitando das nossas fragilidades para imporem os interesses de

3 TRALDI, Mariana. Acumulação por despossessão: a privatização dos ventos para a produção de energia eólica no semiárido brasileiro. 2019. Tese (Doutorado em Geografia) - Instituto de Geociências. Universidade Estadual de Campinas, Campinas, 2019, in passim.

4 MAIA, Fernando Joaquim Ferreira; ARRAIS, Leonardo Antônio Cisneiros; BATISTA, Marcela Peixoto. O Acordo de Paris e a transição energética imposta pelo capital no Brasil. Disponível em: https://www.brasildefatope.com.br/2021/04/20/artigo-o-acordo-de-paris-e-atransicao-energetica-imposta-pelo-capital-no-brasil. Acesso em: 02 jul. 2021.

5 LEFF, Enrique. El desvanecimiento del sujeto y la reinvención de las identidades colectivas en la era de la complejidad ambiental, Polis [En línea], 27, Disponível em: http://journals.openedition.org/polis/862. Acesso em: 13 jun. 2021. 
suas corporações privadas no nosso território. Criam as divisões internas nos países do sul e gostam de se aproveitar destas.

Não é à-toa que, recentemente, a França pediu uma reunião para tratar da nossa Amazônia com um clube de banqueiros (o G-7)6. Observem, Macron não quis se encontrar com os mais atingidos: os latino-americanos, as comunidades e os povos tradicionais, os camponeses, os representantes de países latino-americanos, os peruanos, os colombianos, os bolivianos, os venezuelanos etc. O secretário-geral da ONU nunca pediu a convocação de uma cúpula da organização para tratar seriamente da reforma agrária, da reforma urbana, da defesa das terras indígenas, da diminuição das desigualdades regionais e do controle da remessa de lucros das empresas estrangeiras que exploram o sul global. Ou para exigir a desocupação, pela França, da Guiana (francesa?)7. Mas pediu para tratar da Amazônia...8

É assim que desvelamos o caráter antinacional dessas articulações estrangeiras, pseudoambientalistas, e sua associação com corporações privadas anglo-europeias. Não se pode falar em defesa do meio ambiente sem se modificarem as relações de produção que compõem o espaço. Defesa do meio ambiente sem reforma agrária e urbana, sem defesa das terras indígenas, das comunidades e povos tradicionais, sem diminuição das contradições sociais, sem controle da remessa de lucro das empresas de estrangeiras que exploram o nosso

${ }^{6}$ SOUZA, Renato. Macron convoca o G7 para discutir Amazônia: "Nossa casa queima". Correio Braziliense, Brasília, 22 ago. 2019. Disponível em: https://www.correiobraziliense.com.br/app/noticia/brasil/2019/o8/22/internabrasil,778616/presidente-da-franca-chama-g7-para-discutir-queimada-naamazonia.shtml. Acesso em: 02 jul. 2021.

7 'NÃO SOU Papai Noel': Macron gera revolta em visita à Guiana Francesa (VÍDEO).

Sputinik Brasil, 29 out. 2017. Américas. Disponível em: https://br.sputniknews.com/americas/201710299708769-macron-papai-noelguiana-video/. Acesso em: 02 jul. 2021.

8 SECRETÁRIO-GERAL da ONU pede maior mobilização internacional pela Amazônia. Exame, 26 ago. 2019. Mundo. Disponível em: https://exame.com/mundo/secretario-geral-da-onu-pede-maior-mobilizacaointernacional-pela-amazonia/. Acesso em: 02 jul. 2021. 
país e sem a completa descolonização da América Latina é um mero artifício para disfarçar interesses privados internacionais.

Os temas são relevantes pelo motivo de que o problema ambiental é complexo, passa pela geopolítica, pela ordem econômica e não pode ser tratado sem enfrentar as reformas gerais para superar as contradições sociais e econômicas do Brasil. Pátria, nacionalidade, nacionalismo, soberania nacional, da mesma forma que a defesa da qualidade de vida e do meio ambiente, sempre foram aspirações do nosso povo. Mas, por trás de certos "topos", colocados em discursos, ambientais ou não, de defesa disto ou daquilo "acima de tudo", existem estratégias de legitimação, inclusive jurídicas, de interesses de classe e de atores sociais, principalmente anglo-europeus.

A edição de número 44 , que compõe o volume $n^{0} .20$, foi pensada para discutir temáticas que perpassem esses problemas e propiciem reflexões críticas sobre o meio ambiente e o desenvolvimento em um quadro de desapossamento de terras, de direitos e de renda pela economia global.

A edição organizada reuniu trabalhos submetidos em fluxo contínuo, os quais revelam pela quantidade, profundidade e diversidade, a importância do tema e o interesse em torno das mudanças e desafios ambientais para o globo. $\mathrm{O}$ número apresenta artigos sobre o retrocesso ambiental, sobre a dignidade da natureza e sobre os princípios no direito ambiental constitucional. Abordou-se também a questão do bem viver e da governança da água, a política urbanística e a enfiteuse no direito ambiental.

A revista também traz a discussão da instalação de parques eólicos por empresas estrangeiras, com foco nos contratos de arrendamento rural. Não poderia faltar o problema da sustentabilidade nas licitações, com destaque para a sua dimensão social. A revista analisa também os desafios da saúde suplementar em 
tempos de pandemia e o problema do dano ambiental na responsabilização civil.

O número 44 traz colaborações de grande relevância. Assim, Paulo de Bessa Antunes nos presenteia com o tratamento do princípio da vedação de retrocesso no direito ambiental. Sustenta que a maior ou menor proteção ambiental depende da conjuntura econômica. Ingrid Barbosa e José Rosário, ao abordarem a dignidade da natureza, discutem a ressignificação da dignidade humana para além dos animais humanos, atribuindo-lhe uma vertente ecológica. Sérgio Alexandre tenta compreender a salvaguarda de direitos trazidos pela Constituição de 1988, que são relevantes à tutela de patrimônios naturais e paisagísticos. Busca promover uma análise da consolidação dos princípios constitucionais ambientais. Bruna Nonato, Raimundo Raiol e Romário Rebelo enfrentam o problema do neoliberalismo na política urbanística a partir da discussão de uma ação direta de inconstitucionalidade que resultou numa decisão judicial de inconstitucionalidade parcial e geral de leis do município de Salvador, cujo Plano Diretor foi alterado sem garantir ampla e efetiva participação popular. Anderson Vieira e Larissa Alves sustentam que a extinção legislativa da enfiteuse aumentou potencialmente a insegurança jurídica das relações e a inoficiosidade nas relações jurídicas. Gina Pompeu e Márcia Fernandes refletem criticamente se a compatibilização entre o desenvolvimento econômico e a sustentabilidade implica o questionamento do próprio modelo vigente de desenvolvimento econômico, que tem como centro o mercado. José Irivaldo reflete sobre de que forma se pode manejar a governança de modo a proporcionar uma governança da água baseada na equidade e numa matriz ecológica. Bruno Bastos e Felipe Fraga analisam a necessidade de modificação das regras para o contrato de arrendamento de imóveis rurais para a exploração de energia eólica por parte de pessoas jurídicas que tenham capital estrangeiro. Adriano Mendonça e Liane Pazinato investigam se a dimensão social nos 
processos licitatórios gerenciados pelos órgãos e entidades que compõem a Administração Pública brasileira é subutilizada, acarretando prejuízos ao desenvolvimento econômico ambientalmente sustentável dos municípios. Denise Tanaka verifica o que há de disponível no ordenamento jurídico nacional para o enfrentamento dos desafios da saúde suplementar e da proteção de dados pessoais diante da COVID-19.

Por fim, todas as colaborações resultam de pesquisas no âmbito dos programas de pós-graduação em direito e em áreas afins, preocupadas fundamentalmente com a relação do direito ambiental e o desenvolvimento nas políticas ambientais, na relação entre cidadania, participação social, meio ambiente, nação e crise. A equipe editorial, na pessoa do editor-gerente Jailton Macena, agradece a participação das autoras e dos autores e espera que os ensaios e artigos aqui publicados apontem para o caminho de novas pesquisas.

Recife, João Pessoa, $1^{0}$ de julho de 2021.

\section{Fernando Joaquim Ferreira Maia}

Professor Permanente do Programa de Pós-Graduação em Ciências Jurídicas da UFPB, Editor-Adjunto

\section{REFERÊNCIAS}

HARVEY, David. O novo imperialismo. São Paulo: Edições Loyola, 2003.

LEFF, Enrique. El desvanecimiento del sujeto y la reinvención de las identidades colectivas en la era de la complejidad ambiental, Polis [En línea], 27, Disponível em:

http://journals.openedition.org/polis/862. Acesso em: 13 jun. 2021.

MAIA, Fernando Joaquim Ferreira; ARRAIS, Leonardo Antônio Cisneiros; BATISTA, Marcela Peixoto. O Acordo de Paris e a 


\section{transição energética imposta pelo capital no Brasil.}

\section{Disponível em:}

https://www.brasildefatope.com.br/2021/04/20/artigo-o-acordode-paris-e-a-transicao-energetica-imposta-pelo-capital-no-brasil. Acesso em: 02 jul. 2021.

'NÃO SOU Papai Noel': Macron gera revolta em visita à Guiana Francesa (VÍDEO). Sputinik Brasil, 29 out. 2017. Américas. Disponível em:

https://br.sputniknews.com/americas/201710299708769-macronpapai-noel-guiana-video/. Acesso em: 02 jul. 2021.

SECRETÁRIO-GERAL da ONU pede maior mobilização internacional pela Amazônia. Exame, 26 ago. 2019. Mundo. Disponível em: https://exame.com/mundo/secretario-geral-da-onupede-maior-mobilizacao-internacional-pela-amazonia/. Acesso em: 02 jul. 2021.

SOUZA, Renato. Macron convoca o G7 para discutir Amazônia:

"Nossa casa queima". Correio Braziliense, Brasília, 22 ago. 2019. Disponível em:

https://www.correiobraziliense.com.br/app/noticia/brasil/2019/o8/ 22/interna-brasil,778616/presidente-da-franca-chama-g7-paradiscutir-queimada-na-amazonia.shtml. Acesso em: 02 jul. 2021.

TRALDI, Mariana. Acumulação por despossessão: a privatização dos ventos para a produção de energia eólica no semiárido brasileiro. 2019. Tese (Doutorado em Geografia) - Instituto de Geociências. Universidade Estadual de Campinas, Campinas, 2019. 